\title{
El cine espejo del alma: Relatos sobre afectividad de dos adolescentes resilientes ${ }^{1}$
}

\author{
Blanca Aidee Moya Ortiz ${ }^{2}$ \\ Yessika María Rengifo Castillo ${ }^{3}$
}

Recibido: 30-07-2018

Aceptado: 28-09-2018

\begin{abstract}
RESUMEN
Con esta investigación se utilizó al cine como mediador en la producción de relatos sobre afectividad de dos adolescentes resilientes, que pertenecieron al Sistema de Responsabilidad Penal Para Adolescentes. Para iniciar este estudio las unidades teóricas fueron: adolescencia, conductas transgresoras, afectividad, resiliencia y relato. En el proceso metodológico se utilizaron técnicas como el estudio de caso e instrumentos etnográficos como la observación participante, la entrevista, y finalmente la estrategia que contiene cada uno de estos instrumentos que permitió develar y recopilar la información fueron los talleres de cine, que permitieron el acercamiento a las adolescentes y la narración de relatos sobre afectividad que han venido construyendo. Los hallazgos más importantes son los mismos relatos sobre el afecto producidos por las adolescentes, que desde la teoría de la resiliencia ayudan a los seres humanos a sobreponerse a situaciones adversas. Se podría concluir que los vínculos afectivos, transforman a los sujetos.
\end{abstract}

\footnotetext{
1. La presente investigación se realizó con dos adolescentes resilientes exvinculadas al Sistema de Responsabilidad Penal (SRPA), inició en 2014 con el objetivo de conocer las expresiones y relatos sobre afectividad, que tenía el grupo de adolescentes. Nuevamente, se retoma en el año 2016, con el propósito de conocer los relatos sobre afectividad que han venido construyendo las adolescentes a través del cine como mediador.

2. Licenciada en Humanidades y Lengua Castellana, Fundación Universitaria Monserrate. Especialista en Infancia, Cultura y Desarrollo, y Magister en Infancia y Cultura, Universidad Distrital Francisco José de Caldas. Asistente de la Maestría en Infancia y Cultura, Universidad Distrital Francisco José de Caldas.

Bogotá - Colombia.

Correo: blankitamo@gmail.com

ORCID: https://orcid.org/0000-0002-7765-7233

Google Académico: https://scholar.google.es/citations?hl=es\&user=Ztcng04AAAAJ

3. Licenciada en Humanidades y Lengua castellana, Universidad Distrital Francisco José de Caldas. Especialista en infancia, cultura y desarrollo por Universidad Distrital Francisco José de Caldas. Magister en Infancia y Cultura, de la Universidad Distrital Francisco José de Caldas. Docente.

Bogotá - Colombia.

Correo: yessikarengifocastillo@hotmail.com

ORCID: https://orcid.org/0000-0001-9940-5531

Google Académico: https://scholar.google.com/citations?user=YiKBOKAAAAAJ\&hl=es
} 
Palabras clave: Adolescencia, Conductas Transgresoras, Afectividad, Resiliencia, Relatos.

\title{
The cinema, mirror of the soul: Stories about affectivity of two resilient adolescents
}

\begin{abstract}
This research used the cinema as a mediator in the production of stories about affectivity of two resilient adolescents, who belonged to the System of Criminal Responsibility for Adolescents. To begin this study the theoretical units were adolescence, transgressive behaviors, affectivity, resilience and short stories. In the methodological process, techniques as the case study and ethnographic instruments such as participant observation, interview, and finally the strategy that contained in each one of these instruments that allowed revealing and compiling the information were the cinema workshop, that allowed the approach to the adolescents and the narration of stories about affectivity that they have been building. The most important discovery are the same affection stories produced by the adolescents, which from the resilience theory help human beings to overcome adverse situations. It could be concluded that the affective links transform the subjects.
\end{abstract}

Keywords: Adolescence, Transgressive Behaviors, Affectivity, Resilience, short stories.

\section{Le cinéma, miroir de l'âme: histoires d'affectivité de deux adolescents résilients}

\section{RÉSUMÉ}

Avec cette recherche le cinéma a été le médiateur en la production de nouvelles sur l'affectivité de deux adolescents résilients qui restent au Système de responsabilité pénale pour les adolescents. Au début de la 
recherche les unités théoriques étaient : adolescence, comportements transgresseurs, affectivité, résilience et nouvelle. Dans le process méthodologique des techniques d'étude et instruments ethnographique ont été utilisés par Example : I'observation du participant, l'entretien et finalement la stratégie qui a révélé et compile l'information ont été les ateliers du cinéma qui permettent une approche avec les adolescents et la narration des nouvelles sur l'affectivité qui a été construit. Les découvertes sont les plus importantes sont les nouvelles sur l'affect produits par les adolescents, que depuis la théorie de la résilience aide aux êtres humains à superposer aux situations défavorables. On peut conclure que les liens affectifs transforment aux sujets.

Des mots clés: adolescence, comportements transgresseurs, affectivité, résilience.

\section{Introducción}

La adolescencia es una etapa de grandes cambios físicos y psicológicos; los jóvenes construyen sus propios criterios que determinarán su accionar en los campos políticos, sociales, económicos y culturales. Buscan nuevos referentes más allá de la familia y dados los cambios físicos y hormonales, las vivencias y expresiones de la sexualidad y del erotismo se manifiestan de manera diferente.

Partiendo del interés por explorar el rol del afecto en la vida de los adolescentes, esta investigación se planteó proponer algunas estrategias que facilitaran la recopilación de relatos de dos adolescentes sobre la afectividad, utilizando el cine como mediador. Téngase en cuenta que las adolescentes participes del estudio pertenecieron al Sistema De Responsabilidad Penal Para Adolescentes. Pensamos que posiblemente y de manera hipotética, estas jóvenes resilientes han transformado sus nociones de afectividad a partir de las experiencias vividas, porque en la actualidad no tienen problemas con la ley, se muestran más afectuosas con las personas que las rodean, siendo líderes en diferentes contextos socioculturales. Liderazgo que se traduce en la preocupación de ayudar al otro, y al mismo tiempo de convertirse en ejemplo de sus pares, que han tenido adversidades similares (Langer, 2016). 
Al trabajar desde la óptica de los lenguajes y saberes, esta investigación tuvo cuatro apartados: el primero, es el desarrollo de un marco teórico que dio cuenta de los campos que permean los saberes productos de las interacciones, los adolescentes (en nuestro caso, exvinculados del Sistema De Responsabilidad Penal Para Adolescentes); el segundo, un marco jurídico que permitió conocer las leyes que propenden por el restablecimiento de los derechos de los jóvenes exvinculados al SRPA culturales ${ }^{4}$; el tercero, la presentación de la técnica de estudio de caso y de un enfoque, el cual es la investigación etnográfica, que permitió develar a través de los relatos, los saberes que sobre la afectividad tienen las jóvenes resilientes. Por último, en el cuarto apartado se exponen los resultados y las conclusiones como una polifonía ${ }^{5}$ en la que se conjuga las voces de las adolescentes, de los teóricos y la de las investigadoras, como una aproximación reflexiva acerca de los relatos que sobre el amor, la experiencia y la esperanza, emergieron en el transcurso de la investigación.

\section{La adolescencia}

Hablar de la adolescencia es hablar de la experiencia personal que conlleva importantes cambios físicos, psicológicos, sexuales y sociales que enmarcan la vida de los jóvenes, quienes son sujetos, actores y participes en los diferentes campos de la vida. Sin embargo, muchos no reconocen al adolescente como al niño. Basta con mirar que aun se habla de una población de los "Ados", expresión mediática que tiende a aislar a los individuos jóvenes encasillándolos en un tipo de edad. Lo que ha generado que se establezcan polémicas entre psicólogos, sociólogos, y endocrinólogos-neurólogos, que la han limitado a un periodo de edad. Cuando lo oportuno es crear acuerdos que permitan superar este tipo de inconvenientes en pro de pensar a los adolescentes desde todas sus múltiples dimensiones.

4. Vale la pena señalar que el proceso de restitución de derechos es mutuo, es decir, así como los jóvenes tienen el derecho de restitución, también ellos deberán restituir el derecho y/o reparar el daño causado a sus víctimas.

5. Desde Mijail Bajtin, una polifonía es un conjunto de voces que apunta a una misma temática. Es decir, el conjunto de voces que no se quedan solamente con el acto lingüístico sino que ofrece una perspectiva monológica y abstracta. En ese sentido aparecen las relaciones lógicas que son necesarias para las relaciones dialógicas, que el discurso de dos voces, así como las relaciones de significación objetiva como los enunciados y las posiciones de los diferentes sujetos. 
Dolto (1990) plantea que la adolescencia es una fase de mutación. El adolescente pasa por una muda respecto de la cual nada puede decir, convirtiéndose para los adultos en objeto de cuestionamiento que está cargado de angustia o pleno de indulgencia. Para la autora, la adolescencia se prolonga según las proyecciones que los jóvenes reciben de los adultos y de la sociedad en cuanto a límites de exploración. Propone que los adultos deben estar ahí para ayudar a los adolescentes a asumir las nuevas responsabilidades y a no ser lo que se llama un "adolescente retrasado." En otras palabras, aquel que ha culminado su etapa de adolescencia y aun depende de sus padres para asumir obligaciones.

En ese sentido la adolescencia es aquella vivencia de tránsito desde la niñez a la adultez, momento en la que los sujetos necesitan aclarar fenómenos relacionados con su identidad y con sus proyectos de vida, lo cual les permite encarar con mayor asertividad los retos de una sociedad en la cual deben encajar y seguir construyendo su subjetividad. Estos fenómenos deberían estar enmarcados por el diálogo continuo con sus padres, quienes deberían ser emisores de reflexiones permanentes en favor de la construcción de un joven capaz de transformar su realidad y la del entorno que habita. De acuerdo con Dolto (1990), las personas secundarias (familia, maestros, pares) juegan un papel importante en la educación de los jóvenes durante este periodo. Aunque no estén encargadas de dar dicha educación, todo lo que hacen puede favorecer la expansión de la confianza en sus fortalezas para superar sus temores o al contrario; estimular el desaliento y la depresión. Es decir, que la interacción con los otros juega un papel esencial en la consolidación de la personalidad del adolescente. Interacción que debe darse sobre la base del respeto, que permite aceptar gustos e intereses, que ayuda a reconocer características peculiares que tienen los y las adolescentes. Estos a su vez, pueden hacer uso de herramientas indispensables que les posibilitan estructurar su vida, asumir que son ciudadanos que no pertenecen sólo a sí mismos, a su familia, a sus amigos, etc., pues lo que realizan y dicen afecta a todo un colectivo.

De otro lado, es importante aludir a la sexualidad de los adolescentes, pues en esta etapa del desarrollo se despliegan toda una serie de cambios físicos y emocionales, que según el psicoanálisis es lo que va a marcar la diferencia con respecto a los otros momentos del desarrollo. En palabras de Dolto, "No tienen aún una vida sexual, sino es a través de la imaginación. Con mucha frecuencia, penetran en un falso nivel expansivo de sexualidad, que depende de lo imaginario; la masturbación. En el 
momento difícil en que los jóvenes se sienten incómodos en la realidad de los adultos por falta de confianza en sí mismos, su vida imaginaria les sostiene." (Dolto, 1990, pág.14). Lo anterior denota que los adolescentes que son coartados en su derecho al desarrollo de su libre personalidad, ven en conductas como la masturbación la posibilidad de experimentar y poder ser, superando la depresión que les produce la adultez. Sin embargo, como esa satisfacción se produce desde la imaginación carece de fuerza para ir en busca de la realidad. Es decir, en busca de un par que mantenga la posibilidad del amor y le impulse a salir de esa "posible" trampa que es producto de la falta de escuchar y comprender y de ser escuchado y comprendido por los adultos. Así mismo, la educación es una herramienta fundamental a la hora de promover espacios y estrategias que garanticen en los adolescentes el ser sujetos de derechos en ese juego de polifonías que promueven sus gustos e intereses como ejes esenciales en el cambio de los distintos sectores de una nación.

Las relaciones amorosas se convierten en espacios donde los jóvenes pueden experimentar toda clase de sentimientos hacia una persona que les ayude a ser ellos mismos. Según Dolto (1990), el hecho transcendental que marca la ruptura con el estado de la infancia es la posibilidad de disociar la vida imaginaria de la realidad; el sueño de las relaciones reales. Lo anterior responde a la necesidad de esa interacción permanente con los otros, instaurando espacios en los que el pensamiento converge con el propósito de pensar en un "nosotros" sin dejar de ser "uno". Teniendo en cuenta que cada uno de los seres humanos tiene su propia historia y siente desde su interior un anhelo de libertad, de autonomía, y de tomar posturas personales para encaminar su vida de acuerdo a sus intereses (Tahull, 2016).

La familia seguirá siendo un punto de referencia en la etapa de la adolescencia, ese punto de referencia deberá consolidarse en el diálogo, el respeto y la confianza, teniendo en cuenta que son jóvenes que están ampliando su mundo desde distintas miradas, lo que les permitirá construir la suya, ojalá sin el temor a ser juzgados por no continuar con las expectativas que los padres tenían sobre ellos. Todo lo contrario, sus decisiones deberán ser tomadas como materia prima a la hora de afianzarse como sujetos de derechos, capaces de expresar pensamientos y sentimientos a favor suyo y de su comunidad (Pérez, 2014). En otras palabras, los adolescentes son reformadores del universo en el que están inscritos. La herramienta clave para que esto sea posible es un adecuado uso de comunicación, caracterizado por un aprendizaje reciproco que 
pone a prueba todos los factores sociales y culturales de los que están permeados adolescentes y padres (Ferreyra, 2014).

(Le Breton, 2005) señala que la adolescencia no es un hecho, sino ante todo, una cuestión que atraviesa el tiempo y el espacio de las sociedades humanas. Algunas se preocupan por distinguir las clases etarias y las responsabilidades que les están ligadas. Estas definen un periodo intermediario entre la infancia y la madurez social, de manera precisa o difusa según las situaciones. Otorgan entonces un estatuto específico a los jóvenes en materia de sexualidad o de compromiso en su comunidad. Otras no la tienen en cuenta, y la madurez social se da de forma insensible, sin ceremonias ni atención particular. Una cronología de esta edad, pues, no está necesariamente delimitada y depende de una apreciación cultural infinitamente variable.

Lo anterior pone en evidencia que el periodo de adolescencia no se reduce a cambios físicos, psicológicos y emocionales. La cultura juega un papel esencial, en nuestro caso, es en ella y a partir de ella, donde los jóvenes construyen posturas políticas, sociales y económicas en esa búsqueda constante de reafirmarse como sujetos participativos y transformadores del entorno que habitan.

En ese sentido las prácticas culturales y el uso de medios son instrumentos que comprenden cambios, no sólo a nivel técnico sino también de carácter mental y actitudinal. Teniendo en cuenta que los jóvenes resignifican los textos de acuerdo a sus intereses, gustos y necesidades. En otras palabras, son ellos quienes se empoderan, reinterpretan y revierten lo significados que les presentan los productos mediáticos y las industrias culturales.

Al respecto Germán Muñoz señala en (Reina, 2011, pág.58): "Las percepciones del mundo, las experiencias de espacio y tiempo en la vida de los jóvenes prosumidores mediáticos...Se están alterando profundamente mediante los nuevos medios y las tecnologías de comunicación." Lo anterior denota que estos nuevos lenguajes instauran diferentes acepciones en torno a la percepción y construcción de la realidad, lo que conduce a implementar estrategias desde y fuera del aula que les permita a los adolescentes asumir posturas críticas y propositivas frente a los eventos que este tipo de medios les presenta, con el propósito de que puedan establecer diversas miradas sobre a un mismo acontecimiento. 


\section{Adolescentes en conflicto con la ley}

Dado que las adolescentes del presente estudio estuvieron vinculadas al sistema de responsabilidad penal, consideramos importante desarrollar el concepto de Adolescentes en conflicto con la Ley, desde el enfoque de derechos puesto que este permite reconocer a los y las adolescentes como sujetos que interactúan en un contexto social. Además, el concepto de adolescentes en conflicto con la ley debe diferenciarse de otras denominaciones como "menores delincuentes", "joven delincuente", "precoces delincuentes" o "menor infractor", ya que estas denominaciones consideran a los y las adolescentes como "objetos" y no como sujetos de derechos. Estos adolescentes deben ser tratados y apoyados de manera especial, para fomentar el sentido de su dignidad y los valores que fortalecen el respeto por ellos y por los demás. De acuerdo a lo anterior es importante señalar que se trabajó con adolescentes que presentaron conductas transgresoras generadas por situaciones determinantes en sus procesos afectivos, no se observaron las características de su delito, sino que nos enfocamos hacia el reconocimiento del papel de la afectividad y en los relatos que sobre este tema produjeron, ya que concebimos el afecto como una dimensión fundamental en los procesos de resiliencia que estas jóvenes han tenido.

\section{Conductas transgresoras en adolescentes}

Recordaremos, que la conducta transgresora es una infracción a la ley cometida por niños y adolescentes, la cual puede estar enmarcada por factores como el temperamento ${ }^{6}$. Otro factor lo constituye la separación del hogar por periodos largos, lo que conlleva a una inestabilidad emocional, que se verá reflejada en resentimientos, inseguridades,

\footnotetext{
6. El temperamento tiene una dimensión emocional; pero a diferencia de las emociones tales como temor, excitación y aburrimiento, que van y vienen, el temperamento es relativamente consistente y perdurable. Las diferencias individuales en temperamento, que se piensa surgen a partir de la composición biológica básica de la persona, forman el núcleo de la personalidad emergente. De todas maneras, numerosos estudios (Guzell y VernonFeagans, 2004, Kagan y Snidman, 2004, Arcus y Kagan, 1995, entre otros) sugieren que la experiencia puede moderar o acentuar las tendencias tempranas. Los niños pueden permanecer constantes en la forma en cómo reaccionan. En ocasiones el temperamento se define como la manera característica, biológicamente determinada, en que la persona reacciona a personas o situaciones. El temperamento es el cómo de la conducta: no qué hace la persona sino, cómo lo hace (Thomas y Chess, 1977). Algunos investigadores consideran el temperamento de forma más amplia. Puede ser que el niño no actúe de la misma forma en cada situación. Así mismo el temperamento puede afectar, no solo la forma en que los niños se enfocan y reaccionan ante el mundo exterior, sino la manera en como regulan su funcionamiento mental, emocional y conductual (Rothbart, Ahadi y Evans, 2000).
} 
irresponsabilidad, etc., detonantes esenciales en paso al acto de una conducta delictiva. Lo anterior evidencia la importancia de implementar ambientes seguros que les permitan a niños y adolescentes consolidarse como sujetos armoniosos. Entendiéndose el concepto armonioso como las relaciones equilibradas que se establecen con los otros, en los niveles políticos, sociales, económicos y culturales, relaciones que ayudan a consolidar sujetos participativos y transformadores del contexto que habitan.

Según Winnicott (1991), la destructividad forma parte de la conducta delictiva, en donde la agresión interactúa simultáneamente con el afecto, pero que a través del juego se realiza la contención de dicha destructividad interior; es decir que el niño, a su corta edad retiene sentimientos destructivos o agresivos que algunas veces no expresa con los que ama sino que desahoga a través de actividades diarias como sus juegos, en los que se permite desarrollar algunos brotes de violencia que le hacen sentir y tener el control de su emoción.

Cuando la agresión se genera a través de mordiscos, golpes u otras manifestaciones hacia sus seres queridos, dicha agresión lo que forma es un sentimiento de desesperanza de haber lastimado y de forma indirecta se origina una actitud antisocial. Así mismo Winnicott (1991), refiere que la destructividad caracteriza al niño antisocial cuya personalidad no deja espacio para jugar y lo reemplaza entonces por la actuación. Esta tendencia se reproduce de mayor manera en los niños en los que el ambiente humano en los primeros años de vida, especialmente en la relación con su madre no ha sido de especial cuidado y atención, teniendo en cuenta que de la manera como la madre atienda al niño, se nutre la tendencia innata del mismo para preocuparse por el otro.

Con respecto a lo anterior desde Winnicott se entiende que entre los 6 meses y los 2 años de edad, un niño o niña desarrolla la capacidad de preocuparse por los demás, si el niño no tiene este sentimiento de culpa por el mal que le inflinge a otro, esto se conecta con la incapacidad de preocuparse por sí mismo y por los demás generando la conducta antisocial. La preocupación por el otro es un aspecto importante de la vida social que les permite a los individuos cuidar y darle importancia a los demás, sentir y aceptar la responsabilidad hacia otro, lo cual se adquiere en los primeros años de vida y se refuerza y mantiene en la adolescencia, adultez y vejez. Se entiende que las conductas humanas en especial las fuerzas negativas entre los seres humanos son difíciles de 
controlar. Por tanto, cuando estas conductas son crueles y destructivas las personas deben hacer algo para detenerlas o encauzarlas, y una de las cosas que se realizan para menguar esta condición es volcarse hacia el entorno con el fin de que una autoridad externa ejerza el control sobre aquella conducta. Es decir, que la finalidad de toda agresión es que sea ejercido un control y es allí donde los adultos tienen su principal tarea que se materializa en canalizar esta agresión para que esta no vaya demasiado lejos, identificando herramientas basadas en la autoridad confiable, que le permitan al niño sentirse liberado ante cierto grado de maldad. En otras palabras, se trata de que no pierda el gusto o interés por hacer travesuras, sin que por ello se atente contra la integridad de sí mismo o de los otros, cuidando que el niño no encuentre una autoridad débil y pierda todo el control. De aquí, la importancia de la presencia constante de la madre o un sustituto en el acompañamiento de sus hijos, donde ella genere control de las actuaciones del niño o niña, brinde tranquilidad a la angustia del niño ante situaciones de agresión y genere al niño posibilidades de expresar libremente su vida instintiva, en conclusión si la madre no está presente o no genera el ambiente apropiado, él bebé o niño puede perder la capacidad de preocuparse y se manifestará en condiciones más agresivas o primitivas (roba, hace daño, arma líos), características que varían de acuerdo a su madurez emocional, y es allí donde se puede presentar la desintegración del yo, entendida como la no presencia de vínculos afectivos fuertes, lo que da como resultado inseguridad, desconfianza y carencia de afecto, y conlleva al niño a presentar una conducta antisocial que le permite reintegrarse y sentirse reconocido. Otro aspecto que incide en la tendencia antisocial en los adolescentes es el hecho de tener ausencia de sentimiento de culpa, el cual varía de acuerdo a la concepción que se tenga de lo que es "bueno" y lo que es "malo" ya que la persona puede tener diferentes concepciones acerca de todo. Lo que nos lleva a decir que debe existir una autoridad que regule desde la moral al niño pequeño, antes de que aquel tenga la capacidad de oponer resistencia, es importante que el niño en su formación primaria logre distinguir lo que está bien y lo que está mal.

Estos aspectos como la tendencia antisocial, la incapacidad de sentir preocupación por el otro y la conducta agresiva, se adquieren dentro de los primeros años de vida, se mantienen a través del tiempo y se pueden manifestar con mayor fuerza en la etapa de la adolescencia, generando conductas antisociales que pueden llevar a la delincuencia. De acuerdo a lo anterior es importante destacar que el ambiente familiar tiene gran incidencia en los procesos de desarrollo del niño y el adolescente, si estas 
primeras experiencias están llenas de conflicto y desintegración, si la relación que tiene el adolescente con la realidad externa no se encuentra firmemente arraigada, la personalidad no se encuentra integrada y las formas de manifestar el amor son de características primitivas y destructivas, muy posiblemente esto tendrá negativas repercusiones en la personalidad del joven; necesariamente el niño(a) debe vivir en un círculo de amor y fortaleza para que disminuyan los temores frente a sus sentimientos y fantasías. Es decir, que la contención que ejerce la familia es fundamental para que el niño se aproxime a la realidad con los elementos necesarios para superar cualquier adversidad.

Si el niño no encuentra esto en el hogar comienza a buscar un marco fuera de su hogar, Winnicott (1991) refiere que el niño antisocial simplemente busca un poco más lejos, apela a la sociedad en vez de recurrir a su familia o la escuela para que le proporcione la estabilidad que necesita, a fin de superar las primeras y muy esenciales etapas de su crecimiento emocional. Según Winnicot (1991), cuando un niño roba fuera de su hogar, también busca a su madre, con un mayor sentimiento de frustración y con una necesidad mayor de encontrar, al mismo tiempo, la autoridad paterna que ponga un límite al efecto concreto de su conducta impulsiva y a la actuación de las ideas que surgen en su mente cuando está excitado. Solo cuando la figura paterna estricta y fuerte actúa en el caso del niño es donde éste regresa al amor primario, al sentimiento de culpa $y$ al deseo de reparar. De acuerdo con Winnicott "Comprender que el acto antisocial es una expresión de esperanza constituye un requisito vital para tratar a los niños con tendencia antisocial manifiesta. Una y otra vez vemos como se desperdicia o arruina ese momento de esperanza a causa de su mal manejo o de la intolerancia. Es otro modo de decir que el tratamiento adecuado para la tendencia antisocial no es solamente el psicoanálisis, sino que nos presenta otro tipo de manejos: debemos ir al encuentro de ese momento de esperanza y estar a la altura de él." (Winnicott, 2003, pág. 147). Lo anterior muestra la importancia de la afectividad en los primeros años de vida como eje indispensable, que ayuda a desarrollar actitudes como la preocupación por el otro, la reparación y las diferentes formas de afrontar las situaciones de la vida, que trascienden a distintas edades, desde los vínculos afectivos que cada niño o adolescente ha vivido. En este caso, las adolescentes participes del presente estudio, estuvieron vinculados al sistema de responsabilidad penal por una u otra circunstancia, lo cual devela una fractura en sus trayectorias de vida, pero finalmente resignificaron positivamente las situaciones vividas y hoy se presentan a través de sus vivencias y experiencias como jóvenes resilientes. 


\section{La afectividad}

Los seres humanos estamos hechos de historias que se escriben desde siempre, y que tienen que ver con las experiencias que se tienen con el otro, y con los sentimientos que se tejen con otras personas, animales y cosas, que ayudan a transitar tanto los días felices como los días de tormenta. Los procesos afectivos se desarrollan desde el nacimiento hasta la culminación de la vida, en ese sentido los lazos que tienen madre (o su sustituto) e hijos son esenciales, para todas las situaciones y relaciones que afrontan las personas, tanto internas como externas, este vínculo afectivo entre la madre y el niño se representa a través de abrazos, caricias, palabras, etc., entendiendo que es la primera matriz de la condición humana. Si el niño crece con un vínculo afectivo de confianza, su desarrollo podrá realizarse con plenitud, por ende, dicha situación se convierte en su base de seguridad. Según Cyrulnik (2006), "Existen cuatro tipos de relación de vínculo afectivo: protector, de evitación, ambivalente y desorganizado." A continuación presentamos cada vínculo:

- El vínculo Protector se presenta con mayor frecuencia y es fácil de identificarse y desarrollarse en cada cultura, es aquel en el que el niño al sentirse seguro se separa de su madre para realizar exploración, y posteriormente regresa para compartir sus descubrimientos; Así mismo, el vínculo debe generar confianza en el niño hacia las demás personas, para que éste supere o resuelva la angustia que le produce la separación de su madre, padre u otro familiar, y acepte a otras personas desconocidas, teniendo en cuenta las experiencias que adquiera con ellas, como la felicidad, el sufrimiento, el afecto, entre otras, episodios que le permitirán crecer con seguridad para lograr un desarrollo integral.

- El vínculo de evitación consiste en otra forma de abordar la relación afectiva, a través del juego el niño explora pero no comparte con la madre y ante esta ausencia y el sentimiento de desamparo es difícil de consolarlo, cuando la madre vuelve el niño no va a ella para obtener seguridad sino que suple su ausencia en un elemento que le genere seguridad. Elementos como: juguetes, cobijas, libros, etc. 
- El vínculo afectivo de carácter ambivalente muestra a un niño que no desarrolla su capacidad de exploración cuando su madre está presente, manifiesta angustia cuando su madre desaparece como también en su regreso, es difícil de consolar.

- El vínculo afectivo desorganizado se refiere a aquellos niños que no han podido elaborar estrategias de comportamiento hacia la tranquilidad y exploración.

Lo anterior nos lleva a la necesidad de generar herramientas para evitar que la madre sin desearlo, lleve al niño a tener sentimientos opuestos, inseguros, con los sustitutos afectivos u otras personas por su desesperanza, problemas económicos o emocionales, es allí donde el Estadoy la familia deben proveerle a la madre apoyo afectivo, social, cultural y económico durante los primeros años de su hijo, lo cual garantice al niño un vínculo afectivo seguro, que le ayude a superar problemas que la vida le presente, y a establecer mejores relaciones en los entornos escolares, profesionales y sociales donde interactúe. Se propone brindarles a las familias más vulnerables a través de diferentes instituciones sociales y culturales, programas que fortalezcan las relaciones de vínculos afectivos entre padres e hijos donde estos comprendan que el exceso y la carencia del mismo, sólo darán como resultado niños y jóvenes frágiles dentro de una prisión afectiva entendida como la privación que sufren infantes y adolescentes para establecer relaciones con otros.

\section{Deprivación afectiva}

La deprivación es una conducta que presentan niños, niñas y adolescentes que han vivido experiencias dolorosas, por la desintegración de sus familias, ocasionada por sucesos como la desaparición o pérdida de alguno de sus padres, por el divorcio de los mismos, aun siendo "buenos" y otros no tan "buenos" afectivamente hablando. También se puede presentar deprivación afectiva en hogares conformados sólo por la madre que entrega afecto o por una madre que no es tan afectuosa y en ninguno de estos casos está el reconocimiento y presencia del padre o nunca contaron con un hogar. Según Winnicott (1991), suelen hacerse clasificaciones mixtas:

"a. Según la edad del niño, y también la edad que tenía cuando ese medio suficientemente bueno dejó de existir. 
b. Según el temperamento y la inteligencia del niño.

c. Según el diagnóstico psiquiátrico del niño." (Winnicott, 2003, pág. 203).

Lo anterior se traduce en el detonante que lleva a los niños, niñas y adolescentes a sentir odio, a minimizar su sentido emocional, a alterar su personalidad y a enfrentarse a la realidad vivida de forma traumática, lo que conlleva a una deprivación. Se hace necesario implementar estrategias que permita a los niños y jóvenes, superar las situaciones traumáticas, trasmitiéndoles seguridad, nuevas formas de desarrollo a través de tutores de resiliencia, donde la prioridad sean ellos y sus problemáticas.

De acuerdo con Winnicott (1991), es preferible que las instituciones pequeñas que están a cargo de los niños, niñas y adolescentes, sean matrimonios por la representación de la familia. Lo que indica que estar al interior de una familia aunque no sea la suya, les ayuda a los infantes y jóvenes con problemáticas, lo que reafirma la importancia de una familia como la célula fundamental de la sociedad, en donde los seres humanos se sientan contenidos y puedan construirse como agentes sociales y culturales. En ese sentido las instituciones micro y macro sociales desarrollan procesos terapéuticos que se inscriben en la resiliencia, teniendo en cuenta la mayor información posible sobre el niño, desde el embarazo hasta la situación que causó su deprivación. Esta información es obtenida desde los padres, tíos, abuelos y amigos, desde el mismo niño, niña y adolescentes con el ánimo, de estar enterados de su historia de vida y puedan resignificar su pasado. Cabe recordar que no todas las instituciones cumplen con ese proceso terapéutico, por la cobertura y sus preocupaciones administrativas que no permiten un trabajo personalizado con los niños, niñas y jóvenes. Otro aspecto que les permite sanar su desarrollo emocional es el contacto con objetos de su elección como juguetes, libros, cobijas, el succionar el dedo, el puño, la mano o alguna actividad de tipo genital como la masturbación. Esto se logra al respetar los apegos afectivos que les ayudarán positivamente en el flagelo de la deprivación y lograr desarrollar proyectos de vida. Lo anterior nos lleva a decir que la deprivación es un comportamiento del cual los niños y adolescentes pueden salir, si tienen procesos alternos que les permitan construir nuevos lazos afectivos. 


\section{La resiliencia}

La afectividad es una construcción de diferentes lazos afectivos, en las relaciones que se establecen entre las personas, lo que tiene una relación directa con la resiliencia. Una persona que se siente amada, aun cuando ese ser amado ya no exista sino en su mente y corazón, muy seguramente es resiliente. Ese sentimiento de amor (de otro y por el otro) es lo que le permitirá cambiar o transformar el dolor por un significado que le permita seguir viviendo. Es así como la resiliencia se convirtió en una categoría indispensable en esta investigación, teniendo en cuenta que el grupo de adolescentes exvinculados al Sistema de Responsabilidad Penal Para Adolescentes a pesar de haber trasgredido la norma y con ello pasar por situaciones adversas pudieron resignificar su situación; a través de la expresión de sus sentimientos y de la escucha atenta de sus voces; de esta manera, la narración y el relato fueron medios de resiliencia.

Lo anterior exige instaurar herramientas desde la familia, la sociedad y el Estado, con el propósito de que los y las adolescentes asuman sus historias de vida desde diferentes dimensiones, y a partir de ellas puedan avanzar en su consolidación como sujetos transformadores del entorno y del mundo que habitan. El desarrollo de la resiliencia dependerá del trabajo conjunto de las instituciones educativas y entidades de servicio social dedicadas a la adolescencia y que contribuyen a la ruptura de una mentalidad fracasada, que lo único que genera son pérdidas afectivas. Es decir, que la labor de las entidades institucionales deberá centrarse en mejorar las relaciones interpersonales que son las que generan un estado de plenitud en los distintos campos de su vida.

Asimismo Cyrulnik (2010), afirma: que en el proceso afectivo participan las significaciones de las señales percibidas, lo anterior responde a que los procesos afectivos se construyen de acuerdo a las vivencias que permean a los seres humanos, las cuales permiten continuar o quedarse en un suceso. Sucesos que conllevan a suplir carencias de afecto por dependencias a la drogadicción, alcoholismo, hurto, asesinato, prostitución, microtráfico de estupefacientes o a una vida marcada por el éxito social; caracterizada por un sujeto con relaciones familiares, amorosas e intelectuales equilibradas. De esta forma se ratifica que los vínculos afectivos son la base para un desarrollo integral armonioso. En ese sentido la adolescencia se constituye en el periodo de cambios afectivos. Según Cyrulnik (2010), los adolescentes piensan y exploran 
hechos que marcan su vida y entorno. Es decir, que los hechos que viven los jóvenes son un material constante que transita entre el pasado y el presente, con el que pueden acceder a la comprensión de quiénes son y cómo pueden edificar su propia vida y la del espacio que habitan. Es así, como el proceso de resiliencia se convierte en un instrumento fructífero que posibilita el cambio de una experiencia traumática o dolorosa, por una representación que le permitirá establecer nuevas formas de asumir esa situación.

Se podría decir que los adolescentes que se han establecido a partir de vínculos afectivos seguros toman posturas críticas y propositivas frente a los eventos que les presenta la vida, con recursos variados enmarcados por adecuadas interacciones sociales. Los adolescentes que sufren de miedos a expresar sus sentimientos, se caracterizan por tener relaciones sociales difíciles que en ocasiones terminan con la experimentación de relaciones sexuales tempranas, como forma de suplir esa falta de afecto. Lo que lleva a escenarios de promiscuidad, embarazos no deseados, enfermedades sexuales, circunstancias que terminan lastimándolos más. Por lo que se hace difícil iniciar un proceso de resiliencia, puesto que carecen de la base fundamental que es el proceso de afectividad como mecanismo para confrontar los aciertos y desaciertos.

De acuerdo con Cyrulnik (2010), las relaciones familiares que se dan en torno a múltiples vínculos afectivos aumentan la protección afectiva y en caso de crisis, facilitan una posibilidad de resiliencia. Lo anterior conlleva a implementar enlaces afectivos desde la familia, amigos, docentes, etc., que proporcionen seguridad e independencia en el actuar de los y las adolescentes, llevándolos a afrontar sus debilidades y fortalezas. En relación con la resiliencia como forma de representar los eventos traumáticos de manera que esta representación les sirva para fortalecerse como sujetos, encontramos el relato como instrumento de resiliencia por medio del cual, los y las adolescentes pueden hablar acerca de sentimientos de tristeza, alegría, solidaridad e impotencia, que permean su vida e interpretarlos.

\section{El relato}

El relato es una narración de acontecimientos que se caracteriza por un narrador provisto de una intencionalidad. Es decir, una persona o testigo 
que esté dispuesta a contar los sucesos o la representación que tiene de un hecho, a un lector o grupo, en donde situar el contexto es indispensable a la hora de entender los eventos que se van narrar. En ese sentido, los relatos pueden ser sustentados a partir de lo oral o lo escrito, por la imagen fija o móvil, por el gesto y la combinación ordenada de estos elementos; manifestándose en el mito, la leyenda, la fábula, el cuento, la novela, la epopeya, la historia, la tragedia, el drama, la comedia, el cuadro pintado, el cine, las tiras cómicas, las noticias policiales, la conversación.

Es decir, que el relato está presente en todos los acontecimientos históricos, sociales, culturales, políticos y económicos, que le permiten al hombre consolidarse como sujeto.

En voz de Santamaría (2008):

Relatar es una búsqueda constante e infinita; responde a las preguntas fundamentales que se plantea el hombre: ¿Quiénes somos? ¿Cuál es el origen? ¿Cuál es nuestro destino? ¿Cuál es la verdad de nuestro ser? El hombre no cesa de construir, a través de su imaginario, relatos de los hechos y los gestos de los seres humanos que revelan parcelas de esa verdad. (p.96)

En efecto, el relato sigue instaurándose como el medio por el cual los seres humanos le dan sentido a la realidad, pueden replantear su posición frente a sucesos reales y fantásticos en esa construcción permanente de ser sujetos participativos y transformadores del entorno en el que residen. Además, el relato se establece desde diversas modalidades entre las que se encuentran:

1. El relato oral que se encuentra emparentado con el relato literario. Este último es estudiado y analizado desde múltiples corrientes literarias y cuenta con una ciencia: la narratología. Ahora bien, el relato oral ha permeado todas las construcciones políticas, sociales, económicas y culturales, lo que permite tener distintas miradas de un mismo hecho en ese juego de polifonías que convergen en la reformación del entorno.

La narrativa se caracteriza por el uso de una introducción, un desarrollo y un final. Sin embargo, existen otros elementos que se localizan en otros tipos de narrativa desarrolladas ampliamente. Una narrativa desarrollada cuenta con los siguientes elementos: síntesis, orientación, desarrollo, 
evaluación, resultado y coda. Según Santamaría (2008), no todos los elementos de una narrativa desarrollada son indispensables. Por lo que sugiere unas fases que regulan el enlace lógico de la historia narrada, las cuales son:

a. La fase de situación inicial: hace referencia a la presentación de unos eventos que van permitir el equilibrio y alteración de la historia.

b. La fase de la compilación o transformación: es aquella que permite la alteración de la historia generando una tensión.

c. La fase de las acciones: recoge los hechos que crean la alteración.

d. La fase de resolución o retransformación: responde a la introducción de los acaecimientos que ayudan a reducir la tensión.

e. La fase de la situación final: aclara el nuevo estado de equilibrio obtenido por la resolución de la tensión.

A estas fases mayores se les puede agregar otras dos fases que no son obligatorias, pero ayudan a entender la postura del narrador frente a la historia narrada. Estas son:

f. La fase de evaluación: se encarga de realizar un comentario de los eventos que desarrollo la narración.

g. La fase moral: abarca el significado global de la narración que aparece al inicio o final de la secuencia.

Lo anterior responde a la necesidad de tener elementos claros que permitan la elaboración de una historia o relato asequible al lector. Finalmente son los lectores quienes se identifican con los hechos que se le han presentado a través del relato, como mecanismos en la solución o interrogantes de su diario vivir. Es decir, que una narración estructurada desde la coherencia recrea un proceso dinámico entre quien "cuenta" y quien "escucha", lo que ayuda a la negociación de significados y a la comprensión de los eventos que ocurren en el planeta, de ahí la importancia de estar atentos al desarrollo de la historia, porque luego de esa historia del otro, posiblemente comienza o se entrelaza la mía, y esta dinámica es la que posibilita la creación de mundos posibles. Asimismo Santamaría (2008), plantea analizar los discursos infantiles globalmente haciendo las mismas preguntas con el discurso que se utiliza en los adultos. Sin tratar de contar de una manera infantil, sino de realizar preguntas diferentes. 
En ese sentido los sucesos se construyen de una forma particular, la cual ayuda a ver un acontecimiento desde diferentes matices. A los infantes no les interesa omitir información de un hecho significativo, siempre y cuando sientan confianza en su receptor. La tarea del receptor ha de ser la de elaborar preguntas que logren captar la atención del niño, niña y adolescente partiendo de sus necesidades, gustos e intereses, lo que conlleva a una reflexión de sus historias de vida.

Además, el psicólogo y biólogo Jerome Brunner, en (Santamaría, 2008) define:

...vivimos en un mar de relatos, y como en el proverbio del pez, que va ser el último en descubrir el agua, tenemos nuestras propias dificultades para comprender lo que significa nadar entre relatos. Pero no es por carecer de competencias para dar explicaciones narrativas de la realidad: no es esto. Somos expertos en la materia; nuestro problema es, sobre todo, llegar a ser conscientes de lo que hacemos fácilmente y de manera automática. Un poco como el antiguo problema de la toma de conciencia. (p.98)

Lo anterior nos lleva a pensar en la necesidad de construir una postura exploratoria que le permita a los seres humanos expresar mediante la lectura y la escritura sucesos que enmarcan su devenir histórico. Es decir, que cuando se describe, se pretende que la persona con su imaginación perciba y comprenda los personajes, el objeto o el lugar del que se le habla como si lo tuviera en frente. Describir es representar ideas o seres tal como son. La descripción debe ser fiel, completa y clara, lo que produce impresiones y sentimientos en el leyente u oyente. Según Cyrulnik (2003), todo relato es un instrumento con el que se construye el mundo. Y el ser humano se siente bien en esa representación de mundo, porque identifica su rol, en otras palabras una razón del ser y estar.

En este sentido, el relato es una construcción constante de significados, caracterizados por una o varios acciones. Un relato es la narración de eventos fantásticos o reales, trascurridos en un espacio y lugar. Se trata de presentar hechos de una forma dinámica, enlazando unos con otros hasta llegar a un final. Entonces, el relato es una invitación a adentrarse y crear mundos posibles que le ayuden al hombre a entender y continuar a pesar de las adversidades e incoherencias que el mundo le presenta. 


\section{Narrar para resiliar}

La narración se convierte en un instrumento del que se valen los seres humanos para dar cuenta de sucesos fantásticos o reales, que ocurren en los campos socioculturales. En ese sentido, cuando los individuos atraviesan situaciones adversas, el narrar se convierte en una posibilidad de alejarse, de tomar distancia del hecho, y este distanciamiento de lo real a través de las palabras que lo representan, es un alivio que ayuda a continuar, a lidiar con esos hechos, pues con el relato es como si se domesticaran. Siempre habrá un segundo tiempo para que el sol vuelva, solamente se necesita de seres que estén dispuestos a escuchar, llamados también tutores de resiliencia, y que con su escucha, ofrecen posibilidades para seguir caminando.

Un verdadero tutor de resiliencia es capaz de decir sí cuando todos han bajado la guardia. En palabras de Iñigo Martínez de Mandojana y Sagrario Martín García citados en (Rubio y Puig 2015, pág. 95):

Es ahí donde un verdadero tutor de resiliencia hace su aparición, donde inicia su labor de transformación, cuando todos los demás dicen "no hay solución, este caso nos supera, ya no podemos hacer nada más". Es más, es bastante probable que él ni te quiera cerca, te rechace, o te agarre de la pechera, te raye el coche o tire una piedra...pero confiar en alguien cuando esta con el agua hasta el cuello, es la foto que aparece en el diccionario de los tutores de resiliencia cuando en la letra "i" buscas la palabra incondicionalidad. Todos los poros de tu piel pueden estar diciendo "que se joda, él se lo ha buscado", pero en realidad sabes que más allá de esta situación hay una pequeña esperanza y que merece la pena arriesgarse, apostar por el 13. Ahí empezamos a hablar de un enraizamiento, de una relación de ayuda. (p.95)

Lo anterior nos señala que un verdadero tutor de resiliencia siempre estará dispuesto a no darse por bendecido, porque es capaz de creer, a pesar de las adversidades en esos niños o adolescentes, y esto les permite volver a soñar a recordar sin dolor, a amar a pesar de la neblina. 


\section{Metodología}

El tipo de investigación que se ha implementado como fundamento es la investigación cualitativa, utilizando algunos preceptos teóricos y metodológicos etnográficos, se manejó el estudio de caso de dos jóvenes resilientes, a partir de las siguientes fases: construcción de unas plataformas teórica y metodológica, trabajo de campo, sistematización de hallazgos y análisis de resultados. Teniendo en cuenta que el objetivo principal era conocer los relatos sobre afectividad, de estas dos adolescentes.

La investigación cualitativa es una metodología dirigida a mapas y representaciones de la sociedad caracterizada por una interacción entre sujetos; interacción que se construye abordando sistemas de signos, con producción de significación, con textos producidos por sujetos, con lenguaje, con cultura, con producción de subjetividades y de identidades. El trabajo se realiza colectivamente con el propósito de lograr una descripción e interpretación de los acontecimientos desde los mismos sujetos con quienes se lleva a cabo la investigación, y en esa medida se posicionan ciclos de observación, análisis y reflexión (Ávila, citado por Páramo, 2008, p. 25; Cerda, 2008).

Es decir, que la investigación cualitativa se desarrolló a partir de la descripción, interpretación y reflexión de los fenómenos sociales, lo que facilitó la identificación de los relatos sobre afectividad. Cabe señalar que el estudio de caso es un método de investigación cualitativa que se ha utilizado ampliamente para comprender en profundidad la realidad social y educativa. Para Yin (1989), el estudio de caso consiste en una descripción y análisis detallados de unidades sociales o entidades educativas únicas. Para Stake (1998), es el estudio de la particularidad y de la complejidad de un caso singular, para llegar a comprender su actividad en circunstancias concretas. Es decir, que el estudio de caso genera un análisis profundo de diversos sucesos sociales, que enmarcan el accionar de los hombres. La etnografía, en ese sentido, es un proceso etnográfico que permite comprender los diferentes sucesos que permean a la sociedad, con la finalidad de reformar aquellas prácticas que obstaculizan la armonía en los individuos. Tal es el caso del grupo de adolescentes resilientes, quienes han logrado transformar sus vidas valiéndose del afecto como eje indispensable. Según Jesús Galindo (1998), define: 
La etnografía es un instrumento que potencia la mirada del curioso y del analítico, eso es todo, y con ese campo penetra a todos los campos de las ciencias sociales y del comportamiento, incluso a la emergente ciencia de la comunicación. Toda esta situación puede ser descrita, puede ser percibida en detalle, eso es lo importante. La mirada que descompone en parte todo lo que ve se hace poderosa, la mirada que navega entre mundos distintos puede hacerlo con confianza y seguridad. El sentido es relativo y maravilloso, es posible aceptar tal premisa y continuar conociendo. La etnografía tiene futuro. (p.350)

Lo anterior evidencia que el proceso etnográfico permite comprender los diferentes sucesos que permean a la sociedad, con la finalidad de reformar aquellas prácticas que obstaculizan la armonía en los individuos. Tal es el caso del grupo de adolescentes resilientes, quienes han logrado transformar sus vidas valiéndose del afecto como eje indispensable.

\section{Descripción del proceso metodológico}

\section{La muestra}

Esta investigación se llevó a cabo con 2 adolescentes que oscilan entre los 16 y 17 años, pertenecen a los estratos 2 y 3; provenientes de hogares monoparentales es decir, con figura materna o paterna, aspectos fundamentales en relación a la descripción y análisis, además que permite realizar una reflexión en torno al concepto que se tiene de la afectividad y la resonancia con su familia y demás personas que les rodean. En ellas prima el amor al Hip-Hop que se desarrolla a partir de los cuatros elementos: DJ, Rap, Graffiti, Break dance y el cine, lo que nos pudo señalar algunos de los caminos para acercarnos a sus mundos desde sus gustos, necesidades e intereses.

\section{Descripción de los instrumentos}

Los presentes instrumentos fueron utilizados para recopilar los relatos que sobre afectividad, tenían las adolescentes participes del estudio: 


\section{Observación participante}

Es una técnica que permite observar todas las situaciones que se presentan en una comunidad desde adentro. Es decir, el investigador debe hacer parte de las actividades que ayudan a analizar, interpretar y describir los distintos sucesos. De acuerdo con Rosana Guber (2001) "La observación participante consiste en dos actividades principales: observar sistemática y controladamente todo lo que acontece en torno del investigador, y participar en una o varias actividades de la población" (p.57). La observación participante permitió reconocer y evaluar de manera constante, las circunstancias de estudio.

\section{La entrevista}

Es una práctica social que determina los gustos, necesidades e intereses de un colectivo. Guber (2001), señala que la entrevista "es una relación social a través de la cual se obtienen enunciados y verbalizaciones en una instancia de observación directa y de participación." Desde esa perspectiva, la entrevista se convierte en una técnica que permite el análisis de la información desde lo dicho por las adolescentes de este estudio, dando acceso a las nociones de afectividad que tienen. Es decir, que la entrevista permitió a las entrevistadas expresar lo que saben, piensan y creen sobre la afectividad.

\section{El cine como tutor de resiliencia}

El cine se instaura como mecanismo y/o herramienta de resiliencia que le permite a los sujetos construir nociones de vida. El cine en este contexto investigativo, se propuso como potenciador de relatos sobre afectividad con adolescentes resilientes, lo que llevó a diseñar unos talleres, como estrategia en la cual se combinaban diversos elementos (Aparicio \& Ostos, 2018). En ese espacio- tiempo, cada actividad propuesta tenía un fin, era calculada y reflexionada, de acuerdo a los objetivos planteados. El fin último era visibilizar y potenciar la voz de las jóvenes, sobre las experiencias significativas que habían tenido, relacionadas con el afecto, lo cual se logró, a través del cine. Rubio y Puig (2015), quienes plantean que un tutor de resiliencia:

No tiene porque ser una persona conocida, ni tan siquiera tiene que tratarse de una persona. Un tutor de resiliencia puede encarnarse en una actividad, un interés o una afición. Al fin 
y al cabo, somos seres ocupacionales, y una actividad puede convertirse en un camino, que nos pone en valor, estimula nuestra confianza y nos da seguridad.

Lo que indica que un tutor de resiliencia puede ser una obra de arte, una canción, un poema, una rosa, y en este caso: el superhéroe del cine como mediador.

\section{Taller}

Es una realidad integradora, compleja, reflexiva, en la que se estructuran la teoría y la práctica como ejes fundamentales del proceso pedagógico, orientado a una comunicación permanente con la realidad social. Reyes (2006). En ese sentido, los talleres se convirtieron en un instrumento sensibilizador en torno a las expresiones y relatos sobre la afectividad por parte de las adolescentes. La propuesta tuvo como fin motivar a las adolescentes para que relataran sus diversas nociones de afectividad. La estrategia que se implementó fue "talleres de cine".

Es importante resaltar que todo el trabajo alrededor de los relatos de las adolescentes se hizo siguiendo las siguientes fases:

Fase uno: Se registró la información obtenida de los relatos sobre afectividad del grupo de adolescentes resilientes con grabaciones y descripciones.

Fase dos: Se procedió a organizar y analizar la información que las adolescentes nos brindaron a través de sus relatos, acerca de las concepciones que tienen sobre la afectividad, teniendo en cuenta los fundamentos teóricos que se han desarrollado.

Fase tres: Se trascribieron los relatos producidos por las jóvenes.

Fase cuatro: Se realizó la constatación con la pregunta problema y los fundamentos teóricos. Es importante señalar que se hizo una revisión de un abundante material fílmico que tuvieran como tema, un adecuado manejo de situaciones difíciles. En este ejercicio se eligieron y observaron 23 películas, de las cuales se seleccionaron: 
Cadena de favores, Escritores de la libertad, y Alma de surfista.

\section{Resultados}

De acuerdo a la información obtenida a través de los diferentes dispositivos puestos en escena en los talleres de cine, se construyeron tres categorías para el respectivo análisis:

- Amor

- Experiencia

- Esperanza

A continuación se abordan cada una de las categorías:

\section{Relatos sobre el amor}

Esta categoría aborda los relatos sobre afectividad que produjeron las adolescentes, a partir de distintas experiencias que han tenido en sus vidas. Teniendo en cuenta que el amor es el eje fundamental que le permite al ser humano esa búsqueda incansable de plenitud, que se genera a partir de experiencias, emociones y actitudes.

A continuación se presentan algunos de los relatos sobre el amor de las adolescentes:

"Todo lo que logrado hasta el momento es gracias al amor, a la gente que cree en mí. El final es súper porque la protagonista no se dio por vencida y es una campeona de los deportes. Yo ahora lo soy de mi vida, porque lucho por mis sueños y por el amor a mi familia, a mí misma. No, uno no debe cambiar los finales de las cosas que lo ayudan a ser mejor. Por eso no le cambio nada a la película mejor que se repitan momentos como estos". Estefanía Cortés (16).

"El amor es un sentimiento hermoso que nos ayuda a perdonar sin importar nuestros pecados o fallas y seguir adelante. Es la protección y la confianza." Lorena Vega (17). 
La anterior categoría permite entender que las jóvenes han experimentado el amor con familiares, amigos, entre otros, quienes les han permitido construir sentimientos de afectividad, que las ha ayudado a enfrentar situaciones adversas.

\section{Relatos sobre la experiencia}

La experiencia se define como la capacidad que tienen los seres humanos para transformar su vida y contexto. Al respecto, son todos los conocimientos adquiridos por circunstancias o situaciones vividas que les ayudan a las personas a resignificar los acontecimientos ocurridos, convirtiéndose en referentes de su vida y la de otros (Konieczny, 2015).

A continuación se presentan algunos relatos de las adolescentes sobre la experiencia:

"Porque sé que muchas personas podrían fallarme o lastimarme pero mi familia nunca lo ha hecho, y ellos son los que me dan fuerza para seguir adelante. Y pues de mis actos depende mi destino y debo luchar por ellos." Lorena Vega (17).

"Esta película me hizo pensar que siempre debo luchar por lo quiero porque sólo de mí, depende mi futuro." Estefanía Cortés (16).

Al respecto conviene decir que el grupo de las adolescentes ha hecho de sus adversidades las bases para continuar, para ser referentes de aquellas personas que han confiado en ellas, para dejar huellas desde sus voces.

\section{Relatos sobre la esperanza}

La esperanza es el sentimiento al que se aferran los hombres, en esos ires y venires (Pérez, 2013). Es la certeza que a pesar de las caídas siempre puede haber un nuevo comienzo, recordando que en lo crudo de un invierno puede haber un increíble verano.

A continuación se presentan algunos relatos de los adolescentes sobre la esperanza: 
"De la película vista me llevaría la esperanza, la tolerancia, y la paciencia. Pero sobre todo una parte muy fundamental creer en mí, porque si yo no comienzo haciéndolo nadie más lo hará." Lorena Vega (17).

"La fe y las ganas de seguir adelante eso es la esperanza para mí." Estefanía Cortés (16).

Estos relatos evidenciaron que las adolescentes son conscientes, que a pesar de las adversidades pueden construir un camino, manteniendo latente el anhelo por la esperanza.

\section{Conclusiones}

El trabajo realizado con las jóvenes resilientes constató que la adolescencia es un periodo de cambios físicos, psicológicos, sexuales, y emocionales que determinan su vida. Siendo el amor la fuerza que les ayuda a continuar, a pesar de las adversidades. Su conducta transgresora ha venido siendo sublimada desde el arte, específicamente desde el hip-hop como medio para expresar su inconformidad frente a los sucesos del diario vivir. Sin embargo, el cine se convirtió en un canal audiovisual que les presenta múltiples alternativas de accionar en los sectores socioculturales, convirtiéndose en referentes para su familia y para quienes las ven como líderes que trabajan desde y para la sociedad.

\section{Referencias bibliográficas}

Aparicio, O.Y., \& Ostos, O.L. (2018). Las TIC como herramientas cognitivas para la investigación. Revista Interamericana de Investigación, Educación y Pedagogía, RIIEP, 11(1). https://orcid.org/0000-0003-3535-6288. https://orcid.org/0000-0002-6477-9872

Cerda, G. H. (2008). Los elementos de la investigación. Cómo reconocerlos, diseñarlos y construirlos. Bogotá, Colombia. Editorial El Buho Ltda.

Cyrulnik, B. (2003). El murmullo de los fantasmas. Volver a la vida después de un trauma. Barcelona, España. Editorial Gedisa, S.A.

Cyrulnik, B. (2006). Los patitos feos. La resiliencia: una infancia infeliz no determina la vida. Barcelona, España. Editorial Gedisa S.A. 
Cyrulnik, B. (2010). El amor que nos cura. Barcelona, España. Editorial Gedisa, S.A

Dolto, F. (1990). La causa de los adolescentes. Barcelona. Editorial Seix Barral, S.A.

Ferreyra, H. A. (2014). Mesas Socioeducativas para la Inclusión y la Igualdad. Un programa "De todos con todos". Una experiencia en construcción. Revista Interamericana de Investigación, Educación y Pedagogía, RIIEP, 7(2). DOI: https://doi. org/10.15332/s1657-107X.2014.0002.01

Galindo, C. L. J. (1998). Técnicas de investigación en sociedad, cultura y comunicación. Etnografía. El oficio de la mirada y el sentido. México: Editorial Addison Wesley Longman

Guber, R. (2001). La etnografía método, campo y reflexividad. Bogotá, Colombia: Grupo Editorial Norma.

Guzell, J. R., \& Vernon-Feagans, L. (2004). Parental perceived control over caregiving and its relationship to parent-infant interaction. Child Development, 75(1), 134-146.

Kagan, J., \& Snidman, N. (2004). The long shadow of temperament. Cambridge, MA: Bellknap.

Konieczny, P. (2015). Lorenzo García Aretio: bases, mediaciones y futuro de la educación a distancia en la sociedad digital. Revista Interamericana de Investigación, Educación y Pedagogía, RIIEP, 8(1). DOI: https://doi.org/10.15332/s1657107X.2015.0001.08

Langer, E. (2016). La construcción de confianza para el estudio de prácticas de resistencia en la escolarización de jóvenes en contextos de pobreza urbana. Revista Interamericana de Investigación, Educación y Pedagogía, RIIEP, 9(2). DOI: https://doi. org/10.22490/25391887.1945

Le Breton, D. (1995). Antropología del cuerpo y modernidad/Anthropologie du corps et modernité. Nueva Visión.

Páramo, P. (2008). La investigación en las ciencias sociales. Técnicas de recolección de información. Bogotá, Colombia. Editorial Universidad Piloto de Colombia.

Pérez, T. H. P. (2013). Aproximaciones al estado de la cuestión de la investigación en educación y derechos humanos. Revista Interamericana de Investigación, Educación y Pedagogía, RIIEP, 6(1). DOI: https://doi.org/10.15332/s1657-107X.2013.0001.05

Pérez, T. H. (2014). Colombia: de la educación en emergencia hacia una educación para el posconflicto y la paz. Revista Interamericana de Investigación, Educación y Pedagogía, RIIEP, 7(2). DOI: https://doi.org/10.15332/s1657-107X.2014.0002.06 
Reina, R. C. (2011). Historia, memoria y jóvenes en Bogotá. De las culturas juveniles urbanas de finales del siglo XX a las manifestaciones identitarias juveniles en el siglo $X X I$. Bogotá: Editorial Metamorfosis Social.

Reyes, M. (2006). El taller como una realidad integradora. Recuperado de www. slideshare.net

Rothbart, M. K., Ahadi, S. A., \& Evans, D. E. (2000). Temperament and personality: origins and outcomes. Journal of personality and social psychology, 78(1), 122.

Rubio, J.L. y Puig, G. (2015). Tutores de resiliencia: Dame un punto de apoyo y moveré mi mundo. Barcelona, España. Editorial Gedisa, S.A.

Santamamaría, V. F. (2008). Saberes y lenguajes. Una mirada interdisciplinar hacia los niños y los jóvenes. Bogotá, Colombia. Editorial Universidad Distrital Francisco José de Caldas.

Stake, R. E. (1.998). Investigación con estudio de casos. Segunda edición. Ediciones Morata.

Tahull, J. (2016). Modernidad, educación y género. El proyecto inacabado. Revista Interamericana de Investigación, Educación y Pedagogía, RIIEP, 9(2), 159-178. DOI: https://doi.org/10.22490/25391887.1947

Thomas, A. \& Chess, S (1977). Temperament and development. New York: Bruner/ Mazel.

Winnicott, D. (2003). Deprivación y Delincuencia. Editorial Paidós. Buenos Aires, Barcelona, México.

Yin, R. K. (1989). Estudio de caso Investigación Diseño y Métodos Series. Londres: Sage Publications. 